\title{
Thermal circuit model parameters identification of oil-immersed transformer based on PSO algorithm
}

\author{
Linli Zhang ${ }^{1}$, Lisheng $\mathrm{Li}^{1}$, Bin Jiang ${ }^{2}$, Rong $\mathrm{Li}^{2}$, Hongmei $\mathrm{Li}^{2}$, Xiao Dong ${ }^{2}$ \\ ${ }^{1}$ State Grid Shandong Electric Power Research Institute, Jinan, 250000, China \\ ${ }^{2}$ State Grid Shandong Electric Power Company, Jinan, 250000, China
}

\begin{abstract}
Keywords: power transformer; hot spot; thermal circuit model; PSO algorithm; parameter identification
\end{abstract}

\begin{abstract}
The thermal circuit model of oil-immersed transformer needs to improve its accuracy in predicting the winding hottest-spot temperature, especially in the case of overload and different cooling modes. In the case of overload condition, the estimate values obtained from most existing models are smaller than the actual measurement values, which increase the potential of transformer overheating fault because of the estimate shortage. These limitations are mainly due to the thermal circuit parameters which are deviating when overloaded or having different cooling modes. In order to overcome these limitations, a parameter identification and correction approach based on PSO algorithm is proposed. The approach works on daily load pattern, permits better accuracy and improves the estimation security margin of thermal circuit in the presence of overload condition and different cooling modes.
\end{abstract}

\section{Introduction}

In order to increase system operation margins, a transformer may load beyond its nameplate rating. What's worse, some transformers operate beyond nameplate ratings in peak load period in order to avoid load shedding. The hottest-spot temperature of the winding is a basic criterion which can indicate the dynamic load margin and insulation life loss and detect latent overheat faults [1-4]. Hence, it is important to evaluate the winding hot-spot temperature accurately so that transformers can operate safely and economically. The researches of the winding hot-spot temperature evaluation have been taken for many years and a number of methods and models have been proposed [5-15].

Among the methods, the direct measurement based on the optical fiber is supposed to be the most accurate method [16-18]. However, it isn't suitable for hot-spot temperature predicting and the optical fiber's service life is shorter than the transformers'. The thermal model based on the heating equations and thermal circuits has a better transient accuracy so that it is widely adopted [1][5-8].

The accuracy of thermal circuit models decays in the case of overload and different cooling modes [7][8]. Some model parameters could lead to negative estimate errors which will increase the operation risk when overloaded [1-3][7][8]. These limitations result from the situation that the computation of thermal circuit parameters is based on nameplate data and not suitable for overload condition or different cooling modes.

For those reasons, a parameter identification approach based on PSO algorithm is proposed. It works on daily load pattern and could improve the accuracy and estimation security margin of thermal circuit when overloaded or in different cooling modes. It has been tested and verified by three sets of data furnished by a substation.

\section{Mathematical Model of Thermal Circuit}

Thermal circuit model based on the thermal-electrical analogy, heat transfer theory and lumped parameters was first established by G. Swift [5]. This model focuses on the nonlinear thermal resistances and has been developed to estimate the hot-spot temperature [6-8]. D. Susan improved the thermal circuit model by taking oil viscosity changes and temperature loss variations into account [8]. The model is based on an assumption that the hot-spot temperature is the sum of the 
top oil temperature rise $\Delta \theta_{\text {oil }}$, and the hot spot temperature rise above top oil temperature $\Delta \theta_{\text {hs }}$ The model is depicted in Figure1 and as the detailed report in reference [8].

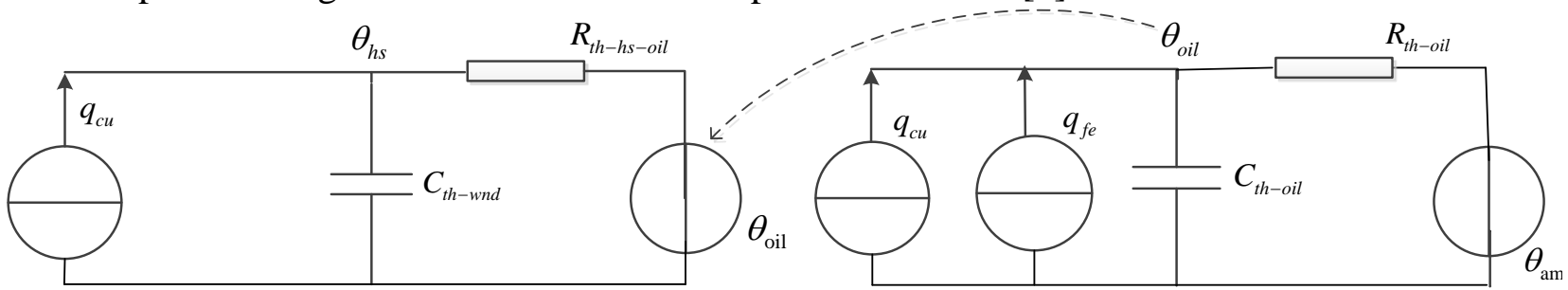

Fig.1. Thermal circuit model

The corresponding mathematical model is expressed as follows:

$$
\left\{\begin{array}{l}
\frac{1+R \cdot K^{2}}{1+R} \cdot \mu_{p u}^{\mathrm{n}} \cdot \Delta \theta_{\text {oil, rated }}=\mu_{p u}^{\mathrm{n}} \cdot \tau_{\text {oil }, \text { rated }} \cdot \frac{d \theta_{\text {oil }}}{d t}+\frac{\left(\theta_{\text {oil }}-\theta_{\text {amb }}\right)^{1+n}}{\Delta \theta_{\text {oil }, \text { rated }}} \\
{\left[K^{2} \cdot P_{c u, p u}\left(\theta_{h s}\right)\right] \cdot \mu_{p u}^{\mathrm{n}} \cdot \Delta \theta_{\mathrm{hs}, \text { rated }}=\mu_{p u}^{\mathrm{n}} \cdot \tau_{\mathrm{wdg}, \text { rated }} \cdot \frac{d \theta_{\mathrm{hs}}}{d t}+\frac{\left(\theta_{h s}-\theta_{\text {oil }}\right)^{1+n}}{\Delta \theta_{h s, \text { rated }}^{n}}}
\end{array}\right.
$$

In the type, $R_{\text {th-hs-oil }}$ is the winding to oil thermal resistance; $R_{\text {th-oil }}$ is the oil to ambient thermal resistance; $C_{\text {th-wnd }}$ is the winding thermal capacitance; $C_{\text {th-oil }}$ is the oil thermal capacitance; $\theta_{\mathrm{hs}}$ is the hot-spot temperature; $\theta_{\text {oil }}$ is the top-oil temperature; $\theta_{\text {amb }}$ is the ambient temperature; $R$ is the ratio of load losses at rated current to no-load losses; $K$ is the ratio of load current to rated current; $\mu_{\mathrm{pu}}$ is the ratio of oil viscosity to oil viscosity at rated oil temperature rise; $\tau_{\text {oil,rated }}$ is the top-oil time constant at rated oil temperature rise, product of rated oil thermal resistance and oil thermal capacitance; $\tau_{\text {wdg,rated }}$ is the winding time constant at rated hot-spot temperature rise and is the product of rated winding to top oil thermal resistance and winding thermal capacitance; $n$ is the empirical constant.

The parameters such as rated load losses $q_{\mathrm{cu}}$ and rated no-load losses $q_{\mathrm{fe}}$ are based on nameplate data or the manufacture tests while $n$ is an empirical constant. However, according to the tests in previous literature [7][8], the accuracy decays obviously under different working condition, especially when overloaded or in different cooling modes. Considering the security margin, the estimate values should be larger than the measured values when overloaded, but no reference takes it into account.

The main reason of accuracy degradation is the parameters deviation under different working conditions and it is necessary to identify the parameters to achieve a satisfactory accuracy. Hence, a novel technique based on PSO algorithm considering the estimation security margin is developed.

\section{Problem Formulation of Parameters Identification}

It is primary to determine two sets of thermal circuit parameters $\mathrm{X}$ respectively for ONAN and ONAF cooling modes to minimize the global error between the estimated values $\Theta_{\mathrm{i}}{ }^{\mathrm{e}}$ and the measured values $\Theta_{\mathrm{i}}{ }^{\mathrm{m}}$ of hot-spot temperature samples. In particular, the negative error and the positive error are processed differently when overloaded. In order to increase the estimation security margin, the positive error (the estimated value is larger) is processed with a little larger tolerance while the negative error is processed with a very small tolerance.

For transformers working in such two kinds of cooling modes, $\Theta_{i}{ }^{e}$ and $\Theta_{i}{ }^{m}$ are respectively divided into two groups to identify two sets of parameters. Hence, the problem is divided into two optimization problems with the same form of objective function as follows:

$$
\left\{\begin{array}{l}
\min f(X) \\
f(X)=\sum_{i} \omega_{i}\left[\Theta_{i}^{e}-\Theta_{i}^{m}\right]^{2}
\end{array}\right.
$$

Noticing that the weighting factor $\omega_{\mathrm{i}}$ is very important and the larger value of $\omega_{\mathrm{i}}$ means the error 
is processed with less tolerance. Therefore, $\omega_{\mathrm{i}}$ can be used to evaluate the relevance of the estimated errors and the load rates, especially under overload conditions. $\omega_{\mathrm{i}}$ is defined as follows:

$$
\omega_{i}= \begin{cases}\frac{I_{i}^{m}}{I_{\text {rated }}} & \text { normal load condition } \\ \frac{I_{i}^{m}}{I_{\text {rated }}} \cdot \alpha^{\left(\theta_{i}^{m}-\theta_{i}^{e}\right)} & \text { overload condition }\end{cases}
$$

The positive error $\left(\theta_{i}{ }^{e}-\theta_{i}{ }^{m}>0\right)$ is more inclination to be accepted considering estimation security margin. So we proposed a novel thermal circuit parameters identification and correction approach with positive error preference strategy. Figure 2 shows evolution of $\omega_{i}$ with estimation error under overload condition.

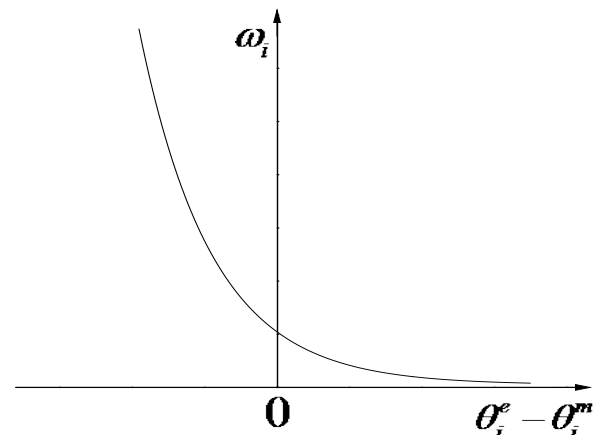

Fig.2. Evolution of weighting factors with estimation error under overload condition

With measured hot-spot temperature samples of transformers working in ONAN and ONAF cooling modes and adopting the thermal circuit model expressed in Eq. (1), two sets of thermal circuit parameters $\mathrm{X}$ corresponding to two sets of cooling modes can be respectively identified via optimization algorithm in the next section.

\section{Proposed Solution via PSO Algorithm}

The afore-mentioned problem is divided into two optimization problems with the same form of objective function (Eq. (2)). The PSO algorithm is a swarm intelligence heuristic algorithm optimization method and has been widely used in engineering optimization. The particle swarm algorithm is very suitable for solving this problem.

The process of implementing PSO for thermal circuit parameters identification is as follows:

Step 1: Choose the set of thermal circuit parameters (Eq. (4)) as particle arrays and randomly generate primary population. 40 particles are generated.

$$
X=\left[\tau_{\text {oil, rated }}, \tau_{\text {wdg, rated }}, \Delta \theta_{\text {oil, rated }}, \Delta \theta_{h s, \text { rated }}, R, n\right]
$$

Step2: Evaluate the fitness function (Eq. (2)) values and compare the fitness value of each particle with its own best location $\mathrm{P}_{\text {best }}$ (the best location means the particle array elements can lead to the best fitness value). If current value is better than best $\mathrm{P}_{\text {best }}$, update $\mathrm{P}_{\text {best }}$ with the current location. Besides, if current value is better than global best location $G_{\text {best }}$, then reset best $G_{\text {best }}$ to the current index in the particle array.

Step3: Update the velocity and location of each particle according to Eq. (5).

$$
\left\{\begin{array}{l}
v_{i, j}(\mathrm{n}+1)=w \cdot v_{i, j}(\mathrm{n})+\mathrm{c}_{1} r_{1}\left[\mathrm{P}_{\text {best }(\mathrm{i}, \mathrm{j})}-x_{i, j}(\mathrm{n})\right]+\mathrm{c}_{2} r_{2}\left[G_{\text {best }(\mathrm{i}, \mathrm{j})}-x_{i, j}(\mathrm{n})\right] \\
x_{i, j}(\mathrm{n}+1)=x_{i, j}(\mathrm{n})+v_{i, j}(\mathrm{n}+1)
\end{array}\right.
$$

Step4: Loop to step2 until meeting the stop criterion (a predefined maximum number of iterations or a sufficiently good fitness value).

\section{Numerical Example}

In order to verify the validity of the method, we have a test on a $220 \mathrm{kV}-75 \mathrm{MVA}$ dual winding transformer. The transformer is equipped with optical fiber temperature sensors and was tested in 
three typical daily load patterns. When the transformer load rate less than $70 \%$, cooling mode is ONAN. When the transformer load rate more than 70\%, cooling mode is ONAF. The load current, winding hot-spot temperature and ambient temperature are measured and recorded at 15-min intervals. Thus we get $\mathrm{N}=96$ sample points. The transformer overloading time lengths and different cooling modes time lengths as shown in table1. Transformer load curves for 3 consecutive days as shown in Figure3 and the measured windings hot spot temperature of day1 as shown in Figure4.

Table.1.Overloading time lengths and cooling modes time lengths

\begin{tabular}{ccccccc}
\hline & \multicolumn{2}{c}{ Over load time(hour) } & \multicolumn{2}{c}{ ONAN (hour) } & \multicolumn{2}{c}{ ONAF(hour) } \\
\hline day & a.m. & p.m. & a.m. & p.m. & a.m. & p.m. \\
\hline day1 & 1.50 & 3.00 & 6.75 & 0.75 & 5.25 & 11.25 \\
day2 & 1.75 & 3.25 & 6.75 & 0.75 & 5.25 & 11.25 \\
day3 & 2.00 & 4.00 & 6.75 & 0.75 & 5.25 & 11.25 \\
\hline
\end{tabular}

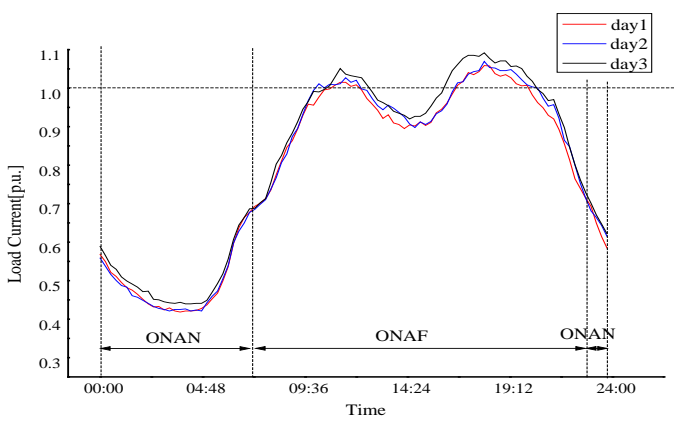

Fig.3. Load curves against time

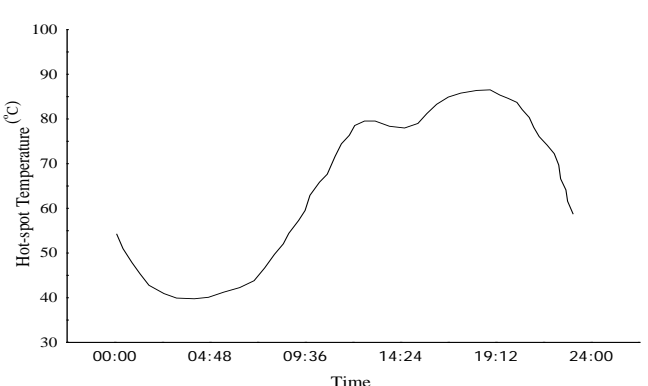

Fig.4. Measured winding HST of day1

\section{Validation tests}

The identification method identifies the corrected thermal parameters (Eq. (4)) by using the data of day1. According to the cooling modes, the data of day1 is divided into two sets to identify two sets of thermal parameters respectively. As depicted in table1 and Figure3, sample data in ONAN cooling modes is used to identify thermal parameters for ONAN cooling modes, so as the ONAF cooling modes. Implement steps in section 4 and the corrected parameters reported in table2.

Table.2. Identification results

\begin{tabular}{cccc}
\hline \multirow{2}{*}{ Parameter } & Values based on nameplate data & Identified values & Identified values \\
\cline { 2 - 4 } & ONAN/ONAF & ONAN & ONAF \\
\hline$\tau_{\text {oil,rated }}(\min )$ & 161.8 & 142.4 & 130.7 \\
$\tau_{\text {wdg,rated }}(\min )$ & 8.7 & 11.2 & 9.9 \\
$\Delta \theta_{\text {oil,rated }}\left({ }^{\circ} \mathrm{C}\right)$ & 30.3 & 32.4 & 29.1 \\
$\Delta \theta_{\text {hs,rated }}\left({ }^{\circ} \mathrm{C}\right)$ & 42.2 & 41.9 & 40.3 \\
$\mathrm{R}$ & 6.18 & 5.89 & 6.93 \\
$\mathrm{n}$ & 0.25 & 0.31 & 0.27 \\
\hline
\end{tabular}

In order to further conduct quantitative analysis, defining the mean squared estimation error MSE and the maximum absolute error value ME during overload period as follows:

$M S E=\frac{\sum_{i=1}^{i=N}\left[\Theta_{i}^{e}-\Theta_{i}^{m}\right]^{2}}{N}$

$M E= \begin{cases}\max \left(\left|\Theta_{i}^{e}-\Theta_{i}^{m}\right|\right) & \text { maximum error is positive } \\ -\max \left(\left|\Theta_{i}^{e}-\Theta_{i}^{m}\right|\right) & \text { maximum error is negative }\end{cases}$

MSE represents the deviation of the estimation value from the measured value and ME represents 
the estimation security margin.

The results of the calibrated model adopting the corrected parameters, the measured winding hot-spot temperatures and the results of the model adopting parameters based on nameplate data are shown in Figure5 (a).By comparing the hot-spot temperature profiles in Figure5 (a), we find that the model with the corrected parameters has a better estimation accuracy than the model with parameters based on nameplate data. In particular, the model with the corrected parameters lead to a positive error (the estimated value is larger) when overloaded. The increase in winding hot-spot temperature estimation accuracy and estimation security margin is of great importance in dynamically full exploitation of transformer load capacity under the precondition of ensuring transformer safe operation.

In order to further prove the validity of the corrected thermal parameters, we estimate the transformer hot-spot temperature values of the next two days according to the load curves. The winding hot-spot temperature curves show in Figure5 (b) and (c). The performance comparison is reported in table3.

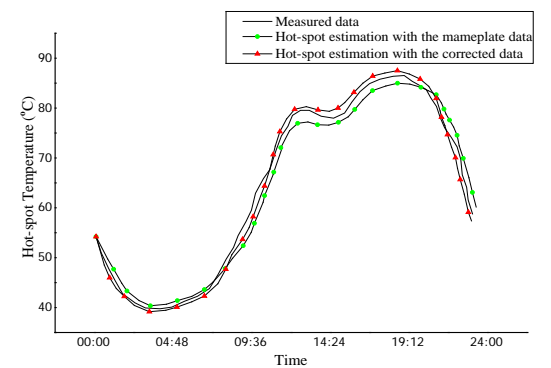

(a) Winding HST of day1

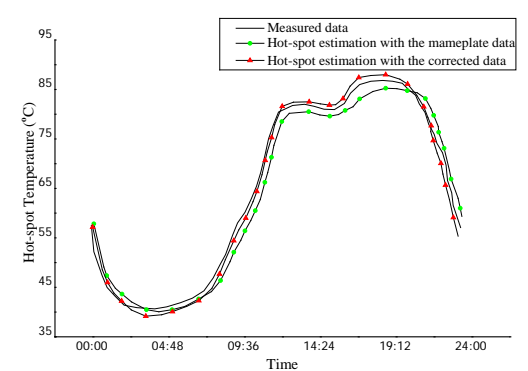

(b) Winding HST of day2

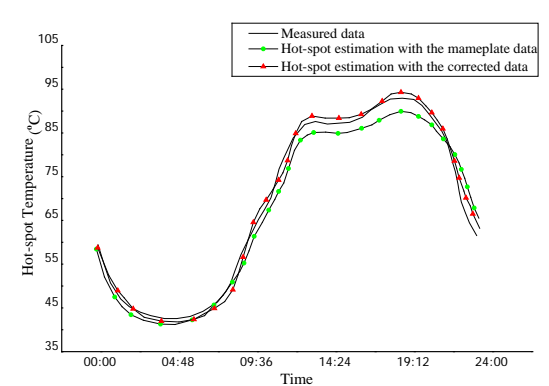

(c) Winding HST of day3

Fig.5. The experimental results of windings HST

Table.3. Comparison results

\begin{tabular}{ccccc}
\hline & \multicolumn{2}{c}{ MSE } & & \multicolumn{2}{c}{ ME } \\
\hline & $\begin{array}{c}\text { with nameplate } \\
\text { parameters }\end{array}$ & $\begin{array}{c}\text { With identified } \\
\text { parameters }\end{array}$ & $\begin{array}{c}\text { With nameplate } \\
\text { parameters }\end{array}$ & $\begin{array}{c}\text { With identified } \\
\text { parameters }\end{array}$ \\
\hline day2 & 10.93 & 3.66 & -4.15 & 2.51 \\
\hline day3 & 13.24 & 4.17 & -4.83 & 2.73 \\
\hline
\end{tabular}

The comparison shows the model with identified parameters has better estimation accuracy and positive estimation error when overloaded, which means the increase of estimation security margin.

\section{Conclusion}

In this paper, a thermal circuit parameters of oil-immersed transformer identification approach based on PSO algorithm was proposed and the thermal circuit model based on the identified parameters was tested and verified by comparing the actual measured data with theoretical data one by one. The results show an increase in the estimation accuracy, especially when transformer works in overload condition and in different cooling modes. In particular, the model with identified parameters leads to positive estimation errors, which reduce the risk of transformer overheating fault caused by estimation shortage and guarantee the estimation security margin. The research in this paper could provide a more reasonable and effective approach for electric power utility to predict transformers' hot spot temperatures.

\section{References}

[1] IEEE guide for loading mineral-oil-immersed transformer, IEEE Standards C57.91-1995, 1996.

[2] Power transformers Part 7: loading guide for oil-immersed power transformers, IEC Standard 60076-7, Ed. 1.0, 2005. 
[3] CIGRE WG 12.09 (Thermal Aspect of Transformers), Survey of power transformer overload field practices, CIGRE 147.1995.

[4] R. Murugan, R. Ramasamy, Failure analysis of power transformer for effective maintenance planning in electric utilities. Engineering Failure Analysis, Vol.55, pp. 182-192, Sep. 2015.

[5] SWIFT G MOLINSKI T S. LEHN A. A fundamental approach to transformer thermal modeling I, theory and equivalent circuit. IEEE Transactions On Power Delivery, 16(2), pp.171-175, 2001.

[6] W.H. Tang, Q.H. Wu, Z.J. Richardson, A simplified transformer thermal model based on thermal-electric analogy. IEEE Trans. Power Delivery, 19 (2004), pp. 1112-1119.

[7] D. Susa, J. Palola, M. Lehtonen, M. HyvarinenTemperature rises in an OFAF transformer at OFAN cooling mode in service. IEEE Trans. Power Del., 20 (2005), pp. 2517-2525.

[8] D. Susa, M. Lehtonen and H. Nordman. Dynamic Thermal Modeling of Power Transformers. IEEE Trans. On Power Delivery, Vol.20, pp.197-204, Jan. 2005.

[9] F. Torriano, M. Chaaban, P. Picher, Numerical study of parameters affecting the temperature distribution in a disc-type transformer winding,Applied Thermal Engineering, Vol.30, Issues 14-15, pp2034-2044, Oct.2010.

[10] Sh. Taheri, A. Gholami, I. Fofana and H.Taheri, Modeling and simulation of Transformer loading capability and hot spot temperature under Harmonic Conditions, Electric Power Systems Research,Vol.86 pp.68-75 May 2012.

[11] Skillen A, Revell A, Iacovides H, et al. Numerical prediction of local hot-spot phenomena in transformer windings[J]. Applied Thermal Engineering, 2012, 36: 96-105.

[12] Sang-Yun Yun,Chang-Ho Park, Il-Keun Song, Development of overload evaluation system for distribution transformers using load monitoring data.International Journal of Electrical Power \& Energy Systems, Vol.44, Issue 1, pp.60-69, Jan.2013.

[13] M.A. Taghikhani, A. Gholami. Prediction and evaluation of the cooling performance of radiators used in oil-filled power transformer applications with non-direct and direct-oil-forced flow,Experimental Thermal and Fluid Science, Vo44, pp392-397 Jan 2013.

[14] Chen W G, Xi H J, Su X P, et al. Application of Generalized Regression Neural Network to Transformer Winding Hot Spot Temperature Forecasting[J]. Gaodianya Jishu/ High Voltage Engineering, 2012, 38(1): 16-21.

[15] Li L, Niu S, Ho S L, et al. A Novel Approach to Investigate the Hot-Spot Temperature Rise in Power Transformers[J]. IEEE TRANSACTIONS ON MAGNETICS, 2015, 51(3): 8400204.

[16] A.B.Loboibeiro,N.F.Eira,J.M.Sousa,P.T.Guerreiro,J.R.Salcedo.Multipoint Fiber-optic hot-spot sensing network integrated into high power transformer for continuous monitoring.IEEE Sensors Journal,8(7):pp. 1264-1267,2008.

[17] Zhang X, Yao S, Huang R, et al. Oil-immersed transformer online hot spot temperature monitoring and accurate life lose calculation based on liber Bragg grating sensor. technology[C]//Electricity Distribution (CICED), 2014 China International Conference on. IEEE, 2014: 1256-1260.

[18] B. Sarkar, C. Koley, N.K. Roy, P. Kumbhakar. Condition monitoring of high voltage transformers using Fiber Bragg Grating Sensor, Measurement, Vol.74, pp.255-267, Oct. 2015. 